\title{
Clinical decision making in cancer care: a review of current and future roles of patient age
}

\author{
Eirik Joakim Tranvåg ${ }^{1,2^{*}}$, Ole Frithjof Norheim ${ }^{1,2}$ and Trygve Ottersen ${ }^{3,4}$
}

\begin{abstract}
Background: Patient age is among the most controversial patient characteristics in clinical decision making. In personalized cancer medicine it is important to understand how individual characteristics do affect practice and how to appropriately incorporate such factors into decision making. Some argue that using age in decision making is unethical, and how patient age should guide cancer care is unsettled. This article provides an overview of the use of age in clinical decision making and discusses how age can be relevant in the context of personalized medicine.

Methods: We conducted a scoping review, searching Pubmed for English references published between 1985 and May 2017. References concerning cancer, with patients above the age of 18 and that discussed age in relation to diagnostic or treatment decisions were included. References that were non-medical or concerning patients below the age of 18 , and references that were case reports, ongoing studies or opinion pieces were excluded. Additional references were collected through snowballing and from selected reports, guidelines and articles.
\end{abstract}

Results: Three hundred and forty-seven relevant references were identified. Patient age can have many and diverse roles in clinical decision making: Contextual roles linked to access (age influences how fast patients are referred to specialized care) and incidence (association between increasing age and increasing incidence rates for cancer); patient-relevant roles linked to physiology (age-related changes in drug metabolism) and comorbidity (association between increasing age and increasing number of comorbidities); and roles related to interventions, such as treatment (older patients receive substandard care) and outcome (survival varies by age).

Conclusions: Patient age is integrated into cancer care decision making in a range of ways that makes it difficult to claim age-neutrality. Acknowledging this and being more transparent about the use of age in decision making are likely to promote better clinical decisions, irrespective of one's normative viewpoint. This overview also provides a starting point for future discussions on the appropriate role of age in cancer care decision making, which we see as crucial for harnessing the full potential of personalized medicine.

Keywords: Decision making, Clinical practice, Age, Age factors, Personalized medicine, Oncology, Priority setting

\section{Background}

Among the many patient characteristics that can affect decision making, patient age is both widely used and heavily discussed. Using age appears intuitive in many settings, but exactly how it should guide clinical decisions is unsettled. Incorporating patient age into

\footnotetext{
* Correspondence: eirik.tranvag@uib.no

'Department of Global Public Health and Primary Care, University of Bergen, Bergen, Norway

${ }^{2}$ Centre for Cancer Biomarkers CCBIO, Department of Clinical Medicine,

University of Bergen, Bergen, Norway

Full list of author information is available at the end of the article
}

decision making is by some seen as unethical and discriminatory. Surveys demonstrate that oncologists use patient age when recommending treatment, even when a large majority at the same time state that they are against such use $[1,2]$. Among the public, empirical studies demonstrate no consensus on the appropriate role of age when allocating resources [3, 4], although a recent systematic review demonstrated that the public generally favors the young over the elderly when having to give priority to one of the groups [5]. Theoretical

(c) The Author(s). 2018 Open Access This article is distributed under the terms of the Creative Commons Attribution 4.0 International License (http://creativecommons.org/licenses/by/4.0/), which permits unrestricted use, distribution, and reproduction in any medium, provided you give appropriate credit to the original author(s) and the source, provide a link to the Creative Commons license, and indicate if changes were made. The Creative Commons Public Domain Dedication waiver (http://creativecommons.org/publicdomain/zero/1.0/) applies to the data made available in this article, unless otherwise stated. 
arguments are used both for [6, 7] and against [8] the relevance of age as a criteria when allocating resources.

To our knowledge there exists no overview of the role of patient age in clinical decision making in cancer care. Most studies describe age in association with some predefined outcome, like treatment selection, survival or shared decision making. A broader examination of how age can influence decision making will benefit both clinical practice and ethical discussion, irrespective of one's view on the proper role of age. If the use of age is considered unacceptable, it is imperative to identify all the ways age actually makes an influence. If every use of age in decision making is discriminatory, every such use of age should be mapped. Equally, if age in some ways can be accepted as guidance for decision making, it is important to know how and to what extent.

With the progress of personalized medicine, attention to individual characteristics will be stronger. In oncology practice it will be increasingly important to understand how patient characteristics affect cancer biology, treatment efficacy, and tolerance [9], as will appropriately incorporating such factors into decision making.

The aim of this study is to provide an overview of the many different ways patient age may guide clinical decisions in oncology. We will identify and discuss associations between age and clinical decisions, and explore how age may be relevant for decision making in the context of personalized medicine.

\section{Methods}

We conducted a scoping review [10] that identified literature covering the use of patient age in cancer diagnostic and treatment decisions. A scoping review is to some extent similar to a systematic review, but there are also several fundamental differences. Systematic reviews address well-defined research questions that can be answered by established methods, and use in-depth assessments of the quality of included studies. Scoping reviews address broader research questions, and can be used to map key concepts of research areas, identify gaps in existing knowledge or merely identify relevant literature on a topic. A scooping review is therefore appropriate to map the many ways patient age may guide clinical decisions in oncology. Scoping reviews do not always assess the quality of included studies, and the synthesis of evidence is typically not quantitative, as it is in systematic reviews [10-12].

We pre-defined our search objective, inclusion criteria and method according to scoping review standards [12]. We searched Pubmed January 212016 by combining search terms related to cancer, age and decision making as follows: "(cancer[title] OR "neoplasms" [MeSH Terms]) AND ("age"[Title] OR "age factors"[Mesh]) AND ("decision making"[MeSH Terms] OR decision
making[Title/abstract])", and limited to references published after 1985. References concerning cancer, with patients above the age of 18 and that discussed age in relation to diagnostic or treatment decisions were included. To include newly published research, we did an updated search May 15 2017. We collected additional references through snowballing and from selected reports, guidelines and previously identified articles.

Duplicates were removed and missing abstracts retrieved. Then the abstracts were screened, and references that fulfilled our aim were included. We applied the following exclusion criteria: age under 18 (as we acknowledge that pediatric oncology is a distinct field of medicine), not medically oriented (as the decisions are not taken by physicians), comments and editorials (as they are opinion pieces) and case reports, preliminary findings and ongoing studies (as they are incomplete). Due to the large number of references identified we do not cite them all. Details on all identified articles, including publication year, country, type and keywords on content were gathered in a table and are available in the Additional file 1: Appendix.

Using the chartered details from all references, we analyzed the content of each reference and identified a main topic. We then organized the references based on the topic under three main categories: Context, Patient, and Intervention. This grouping was done after the search, partly in order to organize our findings, and partly to structure and present it in a clinically relevant and informative manner. If a reference fit more than one category, the one best describing the overall aim of the reference was selected. A narrative summary with selected examples from our search describes findings and how they relate to our objectives.

\section{Results}

Eight hundred sixty three references were identified (see Fig. 1), including both original research and review articles. After removing duplicates, 861 abstracts were screened using the pre-defined criteria. Of the 347 references identified as relevant, 61 were categorized in the Context group, 71 in the Patient group and 215 in the Intervention group.

Our main finding is that age is associated with and partly influences clinical decisions in ways that are both avoidable, as for access to care (age influences how quickly patients are referred to specialized care) or participation in research (older patients are often underrepresented in clinical trials), and unavoidable, as for incidence (strong association between increasing age and increasing incidence rates for cancer) or comorbidity (association between increasing age and increasing number of comorbidities) or treatment outcomes (decreased survival for older patients). In total these publications 


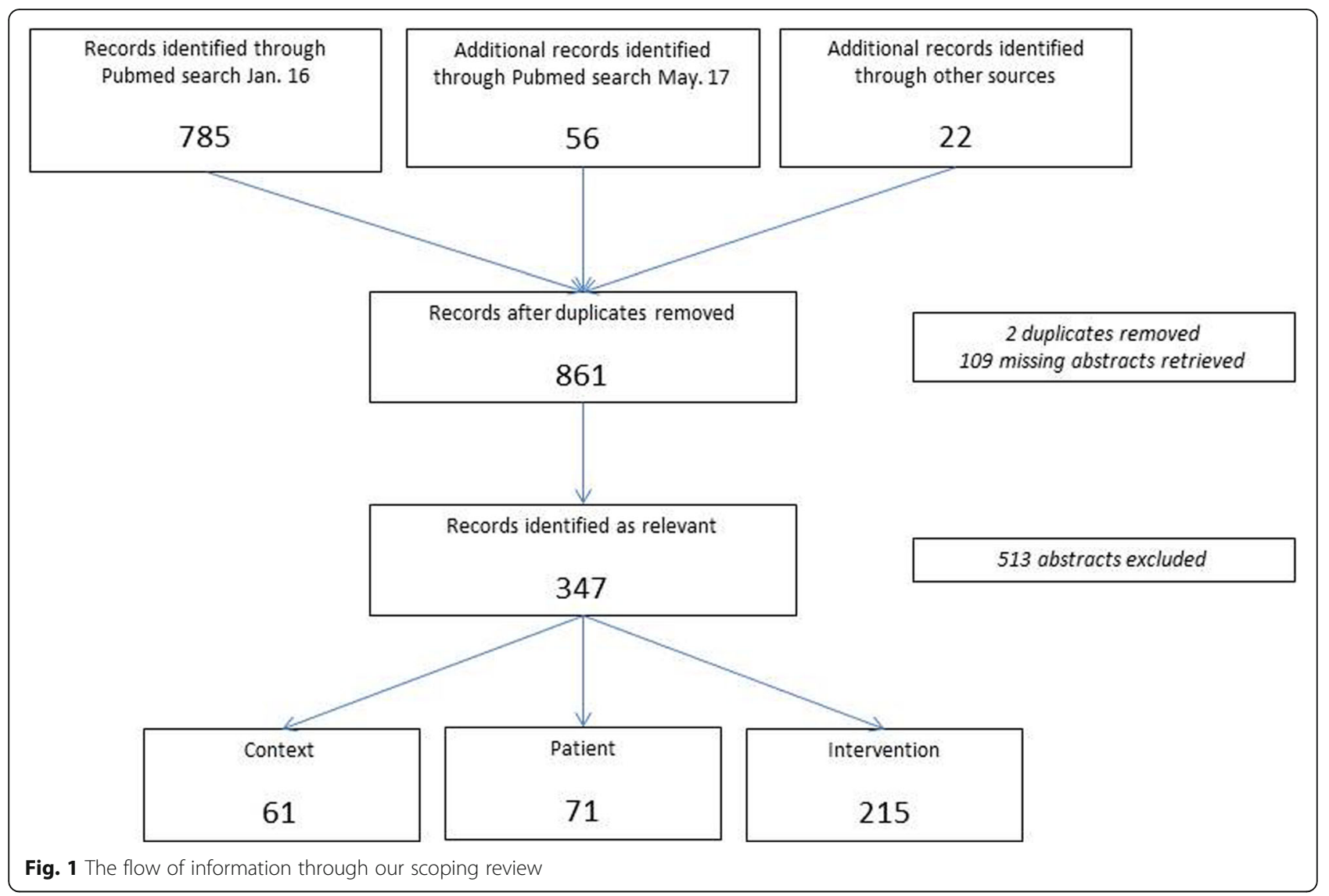

show that patient age can be used - directly or indirectly and consciously or unconsciously - to guide decisions (see Table 1).

\section{Context}

We identified 61 relevant articles associating patient age with factors relevant for the context of a clinical decision. Patient age can influence access to diagnostics and treatment, incidence of cancer, clinical trials and evidence, screening and guideline content.

Access to diagnostics and treatment can be heavily influenced by patient age. Young and old-aged patients recognize fewer cancer symptoms, compared to those aged between 55 and 74 years [13]. And according to the same study by Niksic et al., the number of barriers to present symptoms to a physician decreases with

Table 1 Summary of main findings, with examples

\begin{tabular}{lll}
\hline Category & Factor & Example \\
\hline Context & Access & Age influences how fast patients are referred to specialized care \\
& Incidence & Strong association between increasing age and increasing incidence rates for cancer \\
& Research & Participants in clinical trials often younger than actual disease population \\
& Screening & Strict age cut-offs for inclusion in public screening programs \\
& Guidelines & Clinical guidelines use age thresholds when recommending treatment \\
Patient & Physiology & Age-related declines in CYP enzymes responsible for hepatic drug metabolism \\
& Tumor biology & Proportion of ER and HER2 status in breast cancer varies between age groups \\
& Comorbidity & Association between increasing age and increasing number of comorbidities \\
& Receptivity & Physicians' recommendations are more influential for older patients \\
Intervention & Quality & Older patients tend to receive substandard treatment \\
& Prediction & Risk prediction tools use age for estimations \\
& Treatment outcome & High age is often a predictor of decreased survival \\
\hline
\end{tabular}


increasing age. When examined, age can influence how fast the patient is referred to further investigation and/or specialist care [14]. Older patients with advanced cancers are less likely to be referred to oncology teams [15] compared to younger patients. And when in specialized care, age can influence the decision to refer to certain types of treatment [16].

There is a well-established link between increasing age and increasing incidence rates for cancer worldwide [17]. In Norway, more than $90 \%$ of cancers in men and $85 \%$ in women are diagnosed above the age of 50 , with almost half of the men and $45 \%$ of the women being 70 years or older [18].

Clinical trials are often skewed towards younger and healthier populations compared to the disease population [19], making evidence used in clinical decision weaker. Patients in clinical trials have been shown to be almost 10 years younger than the corresponding Medicare cohort [20]. In the same study, it was demonstrated that studies tend to overestimate survival for older Medicare patients. A systematic review from Zulman et al. shows that one of five trials excludes patients over a certain age, and that almost half of the remaining trials use criteria that disproportionally can exclude older adults [21]. It also found that just one in six trials differentiates benefit by age.

Guidelines for screening use age cut-offs when recommending start and cessation. These are based on estimates of risk, benefit and harm, all of which are influenced by age $[22,23]$. Age can also affect the individual patient or physician's decision to screen. Younger women are more likely to be screened for breast or cervical cancer compared to older women [24, 25], and general practitioners' tendency to screen for prostate cancer using PSA-tests increase with increasing patient age [26].

Several treatment guidelines use age in their recommendations. Some use age when recommending treatment type and length, like the new ESMO guideline on treatment of metastatic non-small cell lung cancer which explicitly emphasizes the age of 70 [27]. The ESMO guideline for treatment of acute lymphoblastic leukemia uses age-adapted treatment protocols in their treatment recommendations [28]. Age can also be listed as one relevant factor for deciding treatment [29], and it can be used as guidance when referring patients to further diagnostics when suspicious of cancer disease [30]. NICE uses age as an explicit cut off when deciding the costeffectiveness of genetic testing for individuals with a family history of breast cancer [31].

\section{Patient}

Seventy-one relevant articles associate patient age with relevant patient factors in clinical decision making. Comorbidity, physiology, tumor biology and patient receptivity for information and communication are all associated with patient age.

A review by Pal and Hurria report that age-related decline in renal blood flow and glomerular filtration rate may affect clearance of cytotoxic agents [9]. Liver size and blood flow decrease by age, and so does effects of many CYP enzymes responsible for hepatic drug metabolism [32]. Compared to younger patients, older patients have reduced stem cell reserve, reduced reserve of functional tissue, and increased risk of comorbidity and polypharmacy [33].

There is a solid link between increasing age and prevalence of comorbidity [34]. In a large observation of newly diagnosed cancer patients, both severity and the mean number of comorbidity conditions increased by age [35]. Findings in a systematic review by Lee et al. suggest that cancer patients with comorbidity receive less chemotherapy and have inferior survival compared to patients without comorbidity [36].

Age is often linked to certain cancer biology and molecular pathology patterns. In breast cancer, medullary and inflammatory disease types are more common in younger patients, while papillary, lobular and mucinous types are more common in older patients [37]. Patients under 45 years of age have almost double the proportion of ER-/HER2- tumors and half the proportion of luminal A tumors than patients above 65 years [38]. Similar ageassociated pathology patterns are seen in other cancer types $[39,40]$.

Age can affect patient's information processing and participation in decision, requiring physicians to adjust their communication and decision style. There is robust evidence of age-related decline in deliberative functions [41], which suggests that information given is processed more slowly. Older patients also tend to make more immediate treatment decisions, with one hypothesis being more limited cognitive resources [42]. A recent systematic review suggests that physicians' recommendation is more influential for older patients [43]. Age is also shown to influence information need: younger patients below the age of 55 require more information than older patients [44].

\section{Intervention}

We identified 215 relevant articles grouped under the broad term interventions. More than half of the references (125) relate patient age to treatment outcome, while others associate age with other relevant factors like prediction tools and quality of treatment.

The outcome of cancer is influenced by the age of the patient, with decreasing survival for older patients [18, $39,40,45,46]$. For many cancer types, high age is a predictor of mortality [47-49]. However, this does not apply exclusively for older patients: Fredholm et al. have 
shown that women with breast cancer under the age of 35 have distinctly worse survival, even with higher intensity treatment [50].

Register studies show that older patients tend to receive substandard treatment: the proportion of lung cancer patients receiving guideline treatment declines with increasing age [51]. Older patients with colorectal cancer were less likely to receive the new anti-angiogenetic drug bevacizumab [52]. Patient age is a significant predictor of type of breast cancer surgery. Younger women receive breast conservation surgery more often than older women [53]. Backing this are many surveys, reporting that physicians do take patient age into consideration when deciding cancer treatment [54-57].

There are many different risk prediction models in use for estimation of survival. One of the best known, Adjuvant! Online(AO) incorporates patient age as a factor [58]. It is shown that $\mathrm{AO}$ overestimates survival in both the younger (below 40 years) and oldest (above 75 years) age groups $[59,60]$. Other prediction tools that are used in oncology also include age, like Predict [61], for deciding treatment after breast cancer surgery, and a new model for predictions of chemotherapy toxicity, developed by Hurria et al. [62].

\section{Discussion}

This scoping review is to our knowledge the first attempt to methodically map out the role of patient age in clinical decision making in cancer care. Our findings suggest that patient age is widely used, directly or indirectly and consciously or unconsciously, to guide clinical decisions.

Patient age is integrated into clinical decision making in a range of ways that in sum makes it not only difficult, but almost meaningless to claim age-neutrality. Consequentially, beliefs that physicians do and even can make decisions completely independent of patient age should be discarded, as such beliefs probably hinders due consideration and discussion of the role of age. Denying any role of age is thus unproductive and can be harmful both for patients and for the debate. Instead, it is time to critically appraise how much and in which ways patient age should guide clinical decisions.

Accepting the relevance of patient age is important in a clinical setting. A more transparent discussion will make clinicians more attentive to their own decision making strategy, thereby facilitating fair and consistent decisions. The opposite, an intentional or unintentional neglect of patient age, is likely to result in poor decisions. In particular, it may lead to unjustified age-based discrimination, in the sense that decisions based on age are not systematically considered or justified. Acknowledging the complex role of age in clinical decision making will also benefit the academic debate. Research is often framed as yes-no decisions on the direct influence of age $[3,4]$, while our findings demonstrate a variety of possible ways age influences clinical decisions.

Deciding when and how patient age can be justified is a value judgement. In some cases, it is unproblematic. Few, if any, will argue that taking into account the welldocumented association between increasing age and increasing incidence of cancer is discriminatory. Nor is anyone protesting that communication between patients and physicians should be adapted to the patient's age and mental status. In these cases the use of patient age is uncontroversial. Conversely, the poor representation of older patients in clinical trial populations needs to be addressed.

Often decisions about individual patients are based on group level data, and age is typically used indirectly as a proxy for individual patient characteristics. In modern cancer care this practice will increasingly be replaced by biomarkers or composite measures. Pharmacodynamic biomarkers can inform the optimal drug dosage for a patient better then estimates based on age [63]. New cancer treatments will increasingly be guided by individual tumor characteristics (see e.g. the Food and Drug Administration's May 2017 approval of pembrolizumab for any solid tumors with specific genetic features [64]). Comprehensive geriatric assessments will better estimate older patients' capacity and tolerance of treatment [65]. And biological age can be estimated through various algorithms providing a better description of a patient's overall mental and physical capacity [66].

For other relationships between patient age and decision making is it more difficult to assess implications for clinical cancer care. Is it a fact, like our review suggest, that older patients receive less and inferior cancer treatment compared to younger patients? Is this true also for new treatments like immunotherapy? If so, is this ethically justifiable? Do oncologists think it is ethically acceptable to limit treatment based on patient age? These questions are important in order to harness the full potential of personalized medicine and require more research. Both empirical and theoretical work is needed.

There are limitations to our study. We have only investigated factors guiding physician recommendations. We acknowledge that deciding treatment is a shared decision between patient and physician, but we still find it valuable to separately investigate these factors. A scoping review does not evaluate the quality of the studies, as is done in systematic reviews. Nevertheless, a scoping review can effectively help identify the many ways age can influence decision making - not claiming that age always affects all factors in the same way all the time. A scoping review like this one can also serve as a valuable basis for future in-depth research on influencing factors. 


\section{Conclusion}

This article has demonstrated how patient age appears to influence a clinical decision in a variety of ways. While arbitrary use of age can lead to unjustified discrimination, the findings suggest that is difficult, if not impossible for a clinician to make an age-neutral decision. Acknowledging the many roles of age and being more transparent about its use can help clinicians make better and more ethical decisions. It can also promote a more open and informed public debate.

\section{Additional file}

Additional file 1: Appendix Details on identified references. Full references, year of publication, country of publication, type of article, subject of article and type of cancer investigated. (XLSX 45 kb)

\section{Abbreviations}

CYP: Cytochromes P450; ER: Estrogen Receptor; ESMO: European Society for Medical Oncology; HER2: Human Epidermal Growth Factor Receptor 2; NICE: The National Institute for Health and Care Excellence; PSA: ProstateSpecific Antigen

\section{Acknowledgements}

Thanks to the members of the Global Health Priorities Research Group at the University of Bergen. Also thanks to Roger Strand, Lars Akslen, Elisabeth Skaar, Siri Rostoft and Oddbjørn Straume for comments on drafts of this article. This work was partly supported by the Research Council of Norway through its Centres of Excellence funding scheme, project number 223250.

\section{Funding}

EJT and OFN are funded by the University of Bergen. TO is funded by the University of Oslo. None of the funding sources had any role in the study design, data collection/analyses, interpretation of data, or writing of the manuscript.

\section{Availability of data and materials}

All data generated during this study are included in this published article and its supplementary information files.

\section{Authors' contributions}

EJT, TO and OFN planned and designed the study. EJT collected and analyzed the data, and wrote the manuscript. TO and OFN critically revised the manuscript. All authors read and approved the final version of the manuscript.

\section{Ethics approval}

Not applicable.

\section{Competing interests}

The authors declare that they have no competing interests.

\section{Publisher's Note}

Springer Nature remains neutral with regard to jurisdictional claims in published maps and institutional affiliations

\section{Author details}

'Department of Global Public Health and Primary Care, University of Bergen, Bergen, Norway. ${ }^{2}$ Centre for Cancer Biomarkers CCBIO, Department of Clinical Medicine, University of Bergen, Bergen, Norway. ${ }^{3}$ Oslo Group on Global Health Policy, Department of Community Medicine and Global Health and Centre for Global Health, University of Oslo, Oslo, Norway. ${ }^{4}$ Division for Health Services, Norwegian Institute of Public Health, Oslo, Norway.
Received: 5 October 2017 Accepted: 30 April 2018

Published online: 09 May 2018

\section{References}

1. National Cancer Equality Initiative. The impact of patient age on decision making in oncology. London: Department of Health; 2012.

2. Werntoft $E$, Edberg A-K. The views of physicians and politicians concerning agerelated prioritisation in healthcare. J Health Organ Manag. 2009;23(1):38-52

3. Rogge J, Kittel B. Who shall not be treated: public attitudes on setting health care priorities by person-based criteria in 28 nations. PLoS One. 2016; 11(6):e0157018.

4. Diederich A, Winkelhage J, Wirsik N. Age as a criterion for setting priorities in health care? A survey of the German public view. PLoS One. 2011;6(8): e23930.

5. Gu Y, Lancsar E, Ghijben P, Butler JRG, Donaldson C. Attributes and weights in health care priority setting: a systematic review of what counts and to what extent. Soc Sci Med. 2015;146:41-52.

6. Williams A. Intergenerational equity: an exploration of the'fair innings' argument. Health Econ. 1997;6(2):117-32.

7. Bognar G. Age-weighting. Econ Philos. 2008;24(02):167-89.

8. Rivlin M: Why the fair innings argument is not persuasive. BMC Med Ethics 2000, 1(1):1

9. Pal SK, Hurria A. Impact of age, sex, and comorbidity on cancer therapy and disease progression. J Clin Oncol. 2010;28(26):4086-93.

10. Arksey H, O'Malley L. Scoping studies: towards a methodological framework Int J Soc Res Methodol. 2005:8(1):19-32.

11. Brien SE, Lorenzetti DL, Lewis S, Kennedy J, Ghali WA. Overview of a formal scoping review on health system report cards. Implement Sci. 2010;5(2):2.

12. Joanna Briggs Institute. The Joanna Briggs institute reviewers' manual 2015: Methodology for JBI scoping reviews. Adelaide: The Joanna Briggs Institute (JBI); 2015.

13. Niksic M, Rachet B, Warburton FG, Wardle J, Ramirez AJ, Forbes LJL. Cancer symptom awareness and barriers to symptomatic presentation in England are we clear on cancer? Br J Cancer. 2015;113(3):533-42.

14. Macleod U, Mitchell E, Burgess C, Macdonald S, Ramirez A. Risk factors for delayed presentation and referral of symptomatic cancer: evidence for common cancers. Br J Cancer. 2009:101:S92-S101.

15. Delva F, Marien E, Fonck M, Rainfray M, Demeaux JL, Moreaud P, Soubeyran P. Sasco AJ, Mathoulin-Pelissier S. Factors influencing general practitioners in the referral of elderly cancer patients. BMC Cancer. 2011;11:5.

16. Pidala J, Craig BM, Lee SJ, Majhail N, Quinn G, Anasetti C. Practice variation in physician referral for allogeneic hematopoietic cell transplantation. Bone Marrow Transplant. 2013:48(1):63-7.

17. Stewart BW, Wild CP. World cancer report 2014. Lyon: International Agency for Research on Cancer; 2016.

18. Cancer Registry of Norway. Cancer in Norway 2015 - Cancer incidence, mortality, survival and prevalence in Norway. Oslo: Cancer Registry of Norway; 2016.

19. Hutchins LF, Unger JM, Crowley JJ, Coltman CA, Albain KS. Underrepresentation of patients 65 years of age or older in Cancertreatment trials. N Engl J Med. 1999;341(27):2061-67.

20. Lamont EB, Schilsky RL, He Y, Muss H, Cohen HJ, Hurria A, Meilleur A, Kindler $\mathrm{HL}$, Venook A, Lilenbaum $\mathrm{R}$, et al. Generalizability of trial results to elderly Medicare patients with advanced solid tumors (alliance 70802). J Natl Cancer Inst. 2015;107(1):336

21. Zulman DM, Sussman JB, Chen X, Cigolle CT, Blaum CS, Hayward RA. Examining the evidence: a systematic review of the inclusion and analysis of older adults in randomized controlled trials. J Gen Intern Med. 2011;26(7): 783-90.

22. Pace LE, Keating NL. A systematic assessment of benefits and risks to guide breast cancer screening decisions. JAMA. 2014;311(13):1327-35.

23. Royce TJ, Hendrix LH, Stokes WA, Allen IM, Chen RC. Cancer screening rates in individuals with different life expectancies. JAMA Intern Med. 2014; 174(10):1558-65

24. Bynum JP, Braunstein JB, Sharkey P, Haddad K, Wu AW. The influence of health status, age, and race on screening mammography in elderly women. Arch Intern Med. 2005;165(18):2083-8.

25. Meissner HI, Tiro JA, Haggstrom D, Lu-Yao G, Breen N. Does patient health and hysterectomy status influence cervical cancer screening in older women? J Gen Intern Med. 2008;23(11):1822-8. 
26. Hayat Roshanai A, Nordin K, Berglund G. Factors influencing primary care physicians' decision to order prostate-specific antigen (PSA) test for men without prostate cancer. Acta Oncol. 2013;52(8):1602-8.

27. Novello S, Barlesi F, Califano R, Cufer T, Ekman S, Levra MG, Kerr K, Popat S, Reck M, Senan S, et al. Metastatic non-small-cell lung cancer: ESMO clinical practice guidelines for diagnosis, treatment and follow-up. Ann Oncol. 2016; 27(suppl 5):v1-v27.

28. Hoelzer D, Bassan R, Dombret H, Fielding A, Ribera JM, Buske C. Acute lymphoblastic leukaemia in adult patients: ESMO clinical practice guidelines for diagnosis, treatment and follow-up. Ann Oncol. 2016;27(suppl 5):v69-82.

29. Henry NL, Somerfield MR, Abramson VG, Allison KH, Anders CK, Chingos DT, Hurria A, Openshaw TH, Krop IE. Role of patient and disease factors in adjuvant systemic therapy decision making for early-stage, operable breast Cancer: American Society of Clinical Oncology endorsement of Cancer Care Ontario guideline recommendations. J Clin Oncol. 2016;34(19):2303-11.

30. National Collaborating Centre for Cancer. National Institute for health and care excellence: clinical guidelines. In: Suspected Cancer: Recognition and Referral. Edn. London: National Institute for Health and Care Excellence (UK); 2015.

31. National Institute for Health and Clinical Excellence. Guidance: familial breast Cancer: classification and Care of People at risk of familial breast Cancer and Management of Breast Cancer and Related Risks in people with a family history of breast Cancer. Cardiff: National Collaborating Centre for Cancer (UK); 2013

32. Kinirons M, O'Mahony M. Drug metabolism and ageing. Br J Clin Pharmacol. 2004;57(5):540-4.

33. Monfardini S. Prescribing anti-cancer drugs in elderly cancer patients. Eur J Cancer. 2002;38(18):2341-6.

34. Janssen-Heijnen MLG, Houterman S, Lemmens VEPP, Louwman MWJ, Maas HAAM, Coebergh JWW. Prognostic impact of increasing age and comorbidity in cancer patients: a population-based approach. Crit Rev Oncol Hematol. 2005:55(3):231-40.

35. Piccirillo JF, Vlahiotis A, Barrett LB, Flood KL, Spitznagel EL, Steyerberg EW. The changing prevalence of comorbidity across the age spectrum. Crit Rev Oncol Hematol. 2008;67(2):124-32.

36. Lee L, Cheung WY, Atkinson E, Krzyzanowska MK. Impact of comorbidity on chemotherapy use and outcomes in solid tumors: a systematic review. J Clin Oncol. 2010;29(1):106-17.

37. Thomas GA, Leonard RCF. How age affects the biology of breast Cancer Clin Oncol. 2009;21(2):81-5.

38. Azim HA Jr, Michiels S, Bedard PL, Singhal SK, Criscitiello C, Ignatiadis M, Haibe-Kains B, Piccart MJ, Sotiriou C, Loi S. Elucidating prognosis and biology of breast cancer arising in young women using gene expression profiling. Clin Cancer Res. 2012;18(5):1341-51.

39. Nazha A, Ravandi F. Acute myeloid leukemia in the elderly: do we know who should be treated and how? Leuk Lymphoma. 2014;55(5):979-87.

40. Schildberg C, Abbas M, Merkel S, Agaimy A, Dimmler A, Schlabrakowski A, Croner R, Leupolt J, Hohenberger W, Allgayer H. COX-2, TFF1, and Src define better prognosis in young patients with gastric cancer. J Surg Oncol. 2013; 108(6):409-13.

41. Peters E, Diefenbach MA, Hess TM, Vastfjall D. Age differences in dual information-processing modes: implications for cancer decision making. Cancer. 2008:113(12 Suppl):3556-67.

42. Meyer BJ, Talbot AP, Ranalli C. Why older adults make more immediate treatment decisions about cancer than younger adults. Psychol Aging. 2007; 22(3):505-24.

43. Puts MTE, Tapscott B, Fitch M, Howell D, Monette J, Wan-Chow-Wah D, Krzyzanowska M, Leighl NB, Springall E, Alibhai SM. A systematic review of factors influencing older adults' decision to accept or decline cancer treatment. Cancer Treat Rev. 2015:41(2):197-215.

44. Ankem K. Factors influencing information needs among cancer patients: a meta-analysis. Library Inform Scie Res. 2006;28(1):7-23.

45. Langstraat C, Aletti GD, Cliby WA. Morbidity, mortality and overall survival in elderly women undergoing primary surgical debulking for ovarian cancer: a delicate balance requiring individualization. Gynecol Oncol. 2011;123(2):187-91.

46. Megwalu UC, Sikora AG. Survival outcomes in advanced laryngeal cancer. JAMA Otolaryngol Head Neck Surg. 2014;140(9):855-60

47. Haymart MR, Banerjee M, Yin H, Worden F, Griggs JJ. Marginal treatment benefit in anaplastic thyroid cancer. Cancer. 2013;119(17):3133-9.

48. Gontero P, Sylvester R, Pisano F, Joniau S, Vander Eeckt K, Serretta V, Larre S, Di Stasi S, Van Rhijn B, Witjes AJ, et al. Prognostic factors and risk groups in
T1G3 non-muscle-invasive bladder cancer patients initially treated with Bacillus Calmette-Guerin: results of a retrospective multicenter study of 2451 patients. Eur Urol. 2015;67(1):74-82.

49. Kutikov A, Egleston BL, Wong YN, Uzzo RG. Evaluating overall survival and competing risks of death in patients with localized renal cell carcinoma using a comprehensive nomogram. J Clin Oncol. 2010;28(2):311-7.

50. Fredholm H, Eaker S, Frisell J, Holmberg L, Fredriksson I, Lindman H. Breast cancer in young women: poor survival despite intensive treatment. PLoS One. 2009:4(11):e7695.

51. de Rijke JM, Schouten L, ten Velde GP, Wanders SL, Bollen EC, Lalisang RI, van Dijck JA, Kramer GW, van den Brandt PA. Influence of age, comorbidity and performance status on the choice of treatment for patients with nonsmall cell lung cancer; results of a population-based study. Lung Cancer. 2004;46(2):233-45

52. Fu AZ, Tsai HT, Marshall JL, Freedman AN, Potosky AL. Utilization of bevacizumab in US elderly patients with colorectal cancer receiving chemotherapy. J Oncol Pharm Pract. 2014;20(5):332-40.

53. Chagpar AB, Studts JL, Scoggins CR, Martin RC 2nd, Carlson DJ, Laidley AL, El-Eid SE, McGlothin TQ, Noyes RD, McMasters KM. Factors associated with surgical options for breast carcinoma. Cancer. 2006;106(7):1462-6.

54. van der Poel MW, Mulder WJ, Ossenkoppele GJ, Maartense E, Hoogendoorn $M$, Wijermans $P$, Schouten HC. Factors that influence treatment decisionmaking in elderly DLBCL patients: a case vignette study. Ann Hematol. 2015; 94(8):1373-9.

55. Keating $\mathrm{NL}$, Landrum MB, Klabunde $\mathrm{CN}$, Fletcher $\mathrm{RH}$, Rogers SO, Doucette WR, Tisnado D, Clauser S, Kahn KL. Adjuvant chemotherapy for stage III colon cancer: do physicians agree about the importance of patient age and comorbidity? J Clin Oncol. 2008;26(15):2532-7.

56. Hurria A, Wong FL, Pal S, Chung CT, Bhatia S, Mortimer J, Somlo G, Hurvitz S, Villaluna D, Naeim A. Perspectives and attitudes on the use of adjuvant chemotherapy and Trastuzumab in older adults with HER-2+ breast Cancer: a survey of oncologists. Oncologist. 2009;14(9):883-90.

57. Ring $A$. The influences of age and co-morbidities on treatment decisions for patients with HER2-positive early breast cancer. Crit Rev Oncol Hematol. 2010;76(2):127-32

58. Ravdin PM, Siminoff LA, Davis GJ, Mercer MB, Hewlett J, Gerson N, Parker $\mathrm{HL}$. Computer program to assist in making decisions about adjuvant therapy for women with early breast cancer. J Clin Oncol. 2001;19(4):980-91.

59. Mook S, Schmidt MK, Rutgers EJ, van de Velde AO, Visser O, Rutgers SM Armstrong N, van't Veer $\amalg$, Ravdin PM. Calibration and discriminatory accuracy of prognosis calculation for breast cancer with the online adjuvant! Program: a hospital-based retrospective cohort study. Lancet Oncol. 2009;10(11):1070-6.

60. Engelhardt EG, Garvelink MM, de Haes JC, van der Hoeven JJ, Smets EM, Pieterse $\mathrm{AH}$, Stiggelbout AM. Predicting and communicating the risk of recurrence and death in women with early-stage breast cancer: a systematic review of risk prediction models. J Clin Oncol. 2013;32(3):238-50.

61. Predict [http://www.predict.nhs.uk/]

62. Hurria A, Mohile S, Gajra A, Klepin H, Muss H, Chapman A, Feng T, Smith D, Sun C-L, De Glas N. Validation of a prediction tool for chemotherapy toxicity in older adults with cancer. J Clin Oncol. 2016;34(20):2366-71.

63. Gainor JF, Longo DL, Chabner BA. Pharmacodynamic biomarkers: falling short of the mark? Clin Cancer Res. 2014;20(10):2587-94.

64. U.S. Food \& Drug Administration: FDA approves first cancer treatment for any solid tumor with a specific genetic feature.: 2017.

65. Puts MT, Hardt J, Monette J, Girre V, Springall E, Alibhai SM. Use of geriatric assessment for older adults in the oncology setting: a systematic review. J Natl Cancer Inst. 2012;104(15):1133-63.

66. Cho $\mathrm{H}$, Park KS, Lim CJ. An empirical comparative study on biological age estimation algorithms with an application of work ability index (WAI). Mech Ageing Dev. 2010;131(2):69-78. 